\title{
COMBINED PRECISE DOCUMENTATION AND VIRTUAL RECONSTRUCTION OF PROPHET NAHUM SHRINE IN ALQOSH, IRAQ
}

\author{
K. Pavelka ${ }^{1}$, J. Šedina ${ }^{1}$, K. Pavelka, jr. ${ }^{1}$ \\ ${ }^{1}$ Czech Technical University in Prague, Faculty of Civil Engineering, Dept. of Geomatics, Thákurova 7, Prague 6, 166 29, (pavelka, \\ karel.pavelka.1, Jaroslav.sedina)@fsv.cvut.cz
}

\author{
Commission II, WG II/8
}

KEY WORDS: Alqosh, Nahum's shrine, Kurdistan, Iraq, documentation, IBMR, heritage

\begin{abstract}
:
In today's world, cooperation between companies that specialize in certain processes is important. There is a long term cooperation between the company GemaArt, focused on historical monument restoration and the Czech Technical University, Faculty of Civil Engineering, dept. of Geomatics, Laboratory of photogrammetry Since 2006, we have finished a lot of projects focused on historical monument care. In the frame of our last project, which was focused on the revitalization and restoration of the Prophet Nahum Shrine in Alqosh in the Iraqi Region of Kurdistan, the detailed documentation and geophysical research of the shrine was carried out in 2018. Close-range photogrammetry, UAV and laser scanning were used for the basic documentation. Several data merge experiments were performed during processing. Significant was the transfer of the main object to the VR, which allows viewing of the object by other professionals without a direct visit to the site and to preserve its original condition before reconstruction.
\end{abstract}

\section{INTRODUCTION}

\subsection{Introduction}

In the north of Iraq, in the Kurdistan region, there is a small historic town called Alqosh. It is known as the site where the Prophet Nahum is buried. The Nahum's shrine was built in the late $17^{\text {th }}$ Century. The building is referred to by the oldest inscription found in the shrine: "I have built for You a stately house; a place where You may dwell forever; The year of worldly redemption (5440/1679-80)". The shrine was tied to the Jewish community for a long time and used as a synagogue. The building itself was rebuilt several times, most recently about a century ago. Although it is demonstrably a shrine in Alqosh, it is not clear whether Nahum was actually buried there. Many historians have spoken about other places. But it is certain that Alqosh has become a place of pilgrimage, as Layard describes in his memories (Layard, 1853). Thousands of believers came to Alqosh on the Feast Shavuot during that time. But after the political and territorial changes following World War II, it changed and since 1948 there are no Jews. The shrine has not been maintained and recently its condition has deteriorated so much that it threatened to totally collapse. At least a temporary roof was built over the shrine.

The state of the shrine in 2018 was on the verge of collapse. Thanks to the efforts of ARCH International, shrine reconstruction started. ARCH International (Barez, 2019) is focused on the protection of cultural heritage especially in danger zones. Based on cooperation with the GemaArt Company, Czech Republic, repair of the shrine and its subsequent reconstruction was started in 2018. Basic documentation was carried out by the Czech Technical University in Prague, Faculty of Civil Engineering, dept. of Geomatics.

The basic processes of preserving cultural heritage include accurate documentation of objects (Barrile, 2016) (Hassani, 2015). Currently, it is implemented by various technologies into a 3D model (Faltynova, 2015) (Sedina, 2017) (Sedina, 2018a).

\subsection{Project and research description}

The very first step was to have an accurate documentation capturing the existing state (Aslan, 2016) (Remondino, 2011). The measurement of the shrine and nearby neighbourhood was carried out in two phases.

\subsection{Phase one}

The first preliminary documentation was carried out in January 2018 by a laser scanning method using the Faro laser scanner and the close-range photogrammetric method IBMR (Image Based Modeling and Rendering). The laser scanning was primarily used due to its exact special documentation of the current state of the structure. A number of the 98 scans of the previously chosen locations were taken from the total data volume of $35 \mathrm{~GB}$, including the textural information recorded by the integrated camera into the scanner. In addition to this, approximately 2000 pictures were taken with the photogrammerical IBMR method by the Canon Mark 5D calibrated camera. Finally, the aerial photogrammetry method was used for the processing of aerial photos (Matouskova, 2016b) (Sedina, 2018b) (Faltynova, 2016) (Sedina, 2015), with about 100 aerial pictures taken by RPAS (Remotely Piloted Aircraft System) DJI Phantom 4 for the creation of an ortophoto of the nearest neighbourhood of the shrine (fig.1-2, fig.6). 


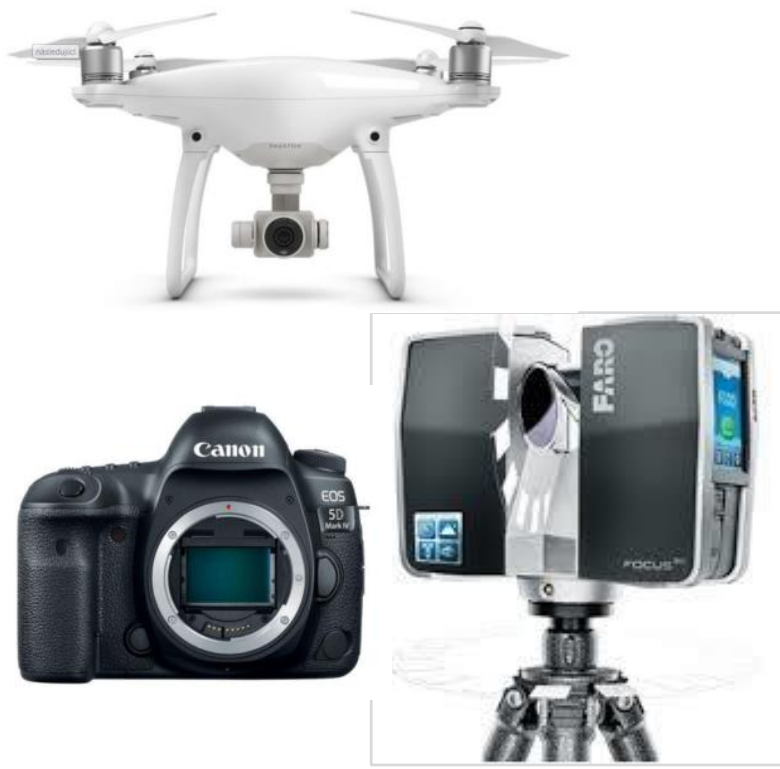

Figure 1. Instruments used: Canon D45 Mark II calibrated camera, DJI Phantom 4 drone and a Faro laser scanner

The laser scanner data was registered to the detail model that contains about 100 million points. It was necessary to decimate the data to half its volume for the resulting 3D model. The data registration was processed on a powerful workstation in late January as a primary model, which was used for basic works and analysis. A meshed shrine model was created in February, which included a registered point cloud as the basic documentation of the partially collapsed Nahum's shrine. Laser scanned data was processed in Faro Scene and Geomagic Studio software.

Basically, Agisoft Photoscan was used, and later Reality Capture for the joining of both laser scanned data and photogrammetric data (fig.3-4).

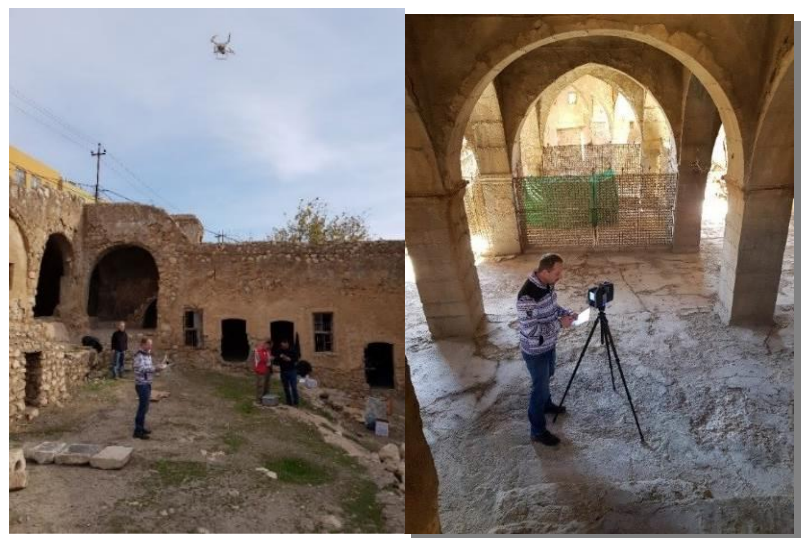

Figure.2. First picture: an example of measuring by the Faro laser scanner, second picture: view of the digital scanning by RPAS (Remotely Piloted Aircraft System) DJI Phantom 4

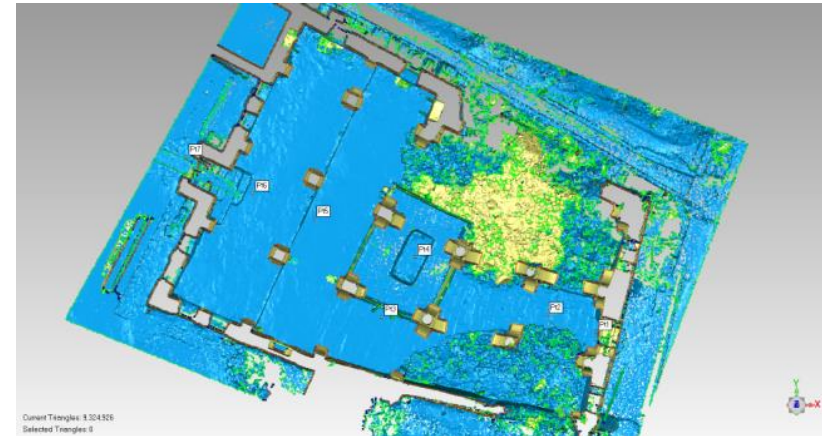

Figure 3. Orthogonal data projection of the shrine from the Faro laser scanner

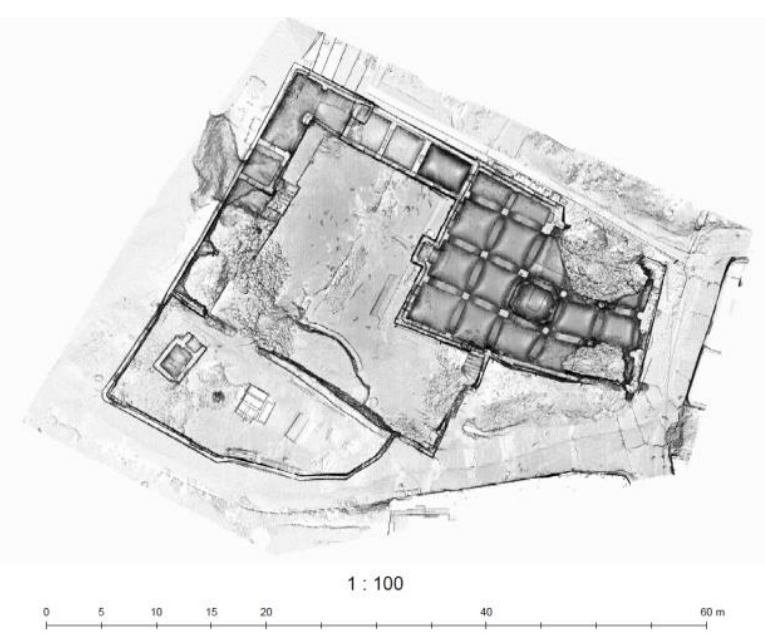

Figure 4. Plan of the whole object with Nahum's shrine from the point cloud (created by IBMR technology) - ortho-view

The photogrammetric date was processed using the IBMR method, e.g. the resulting cloud containing 150 million points. The picture processing was carried through automatically and was going on for about 3 days on a graphical workstation with an i9 processor, 64GB RAM and the Nvidia 24GB graphic card.

The results of all this processing was a textured point cloud that was meshed into the TIN model and covered by texture. It is possible to form from both of these models another output e.g. cuts or profiles, orthophotos and highly precious plans (fig.5).

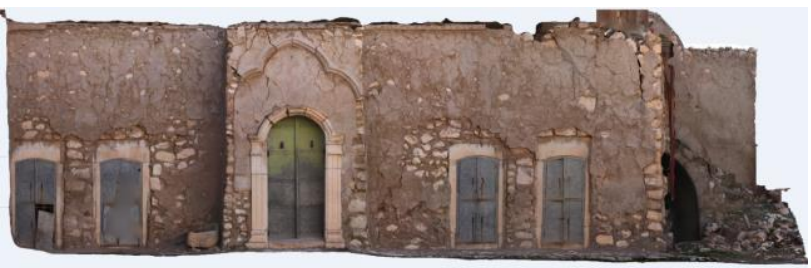

Figure 5. Example of an orthophoto of the northern wall of the Shrine, photogrammetric IBMR technology

The orthophoto plan of the Nahum's shrine and near neighbourhood was processed from the aerial data. 


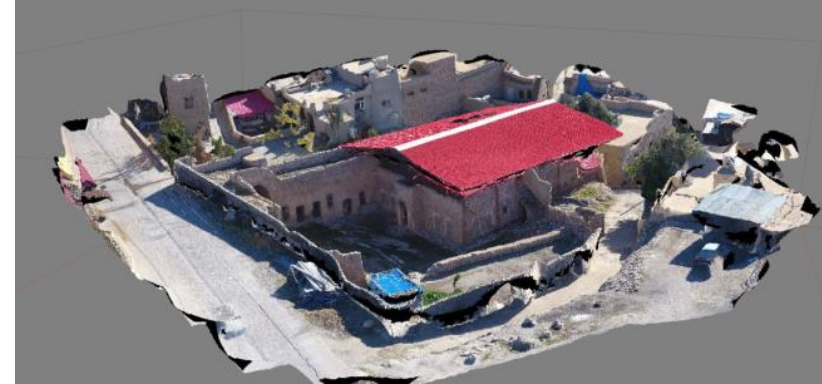

Figure 6. Example of the isometric view of the $3 \mathrm{~d}$ model processed from the aerial data (DJI Phantom 4 with $4 \mathrm{k}$ camera

After several days of documentation of the current state, work was started on securing the object and removing the material from the collapsed parts of the shrine. Beginning in March, the measuring campaign was done. It was focused on the documentation of the interior after the collapsed material removal.

\subsection{Phase two}

In April, after new measurement, a new (second) model was created. This model documented the new stay of the shrine after the collapsed material removal and the static securing of the construction (using timber, tension belts and iron supports).

The purpose of the geodetic works was for the documentation of the new state and the virtual addition of the missing parts of the shrine based on construction analysis, archival original photographs and films.

After the removal of debris from the collapsed vaults and walls, new unknown structural parts were found (important object parts like foot pillars, tiled floor and some ceramic artefacts (Matouskova, 2016a).

The IBMR method was re-used (Sedina, 2015) for the phase two documentation. Around 2000 images were taken again, including a very detailed documentation of existing and discovered inscriptions and fragments (shards, shrine construction components, found ceramic containers in vaults, particularly the south wall).

All details were documented separately and a 3D model was created - these can be used for precise visualization, text analysis of inscriptions on walls or possible $3 \mathrm{D}$ printing of suitable objects.

Next, technical pits were also documented in selected parts of the shrine to ensure the structural analysis of the heavily damaged building.A new model of the shine was created by joining the intact parts from first model with the documented new stay. Phase two used the photogrammetric method for the modeling of the changed parts. Digital modeling and analysis was done in Agisoft Photoscan Reality Capture and Geomagic Studio software's like in documentation phase one.

Virtual analyses of the missing parts supplementation of the object were complicated and time-consuming. At the end of April, the 3D model of the possible reconstruction of the Nahum's shrine was completed. It was a lot of work and testing to search for the right technology and experimenting. A number of photos were masked - mainly used timber, tension belts and iron supports to get clear 3D model.

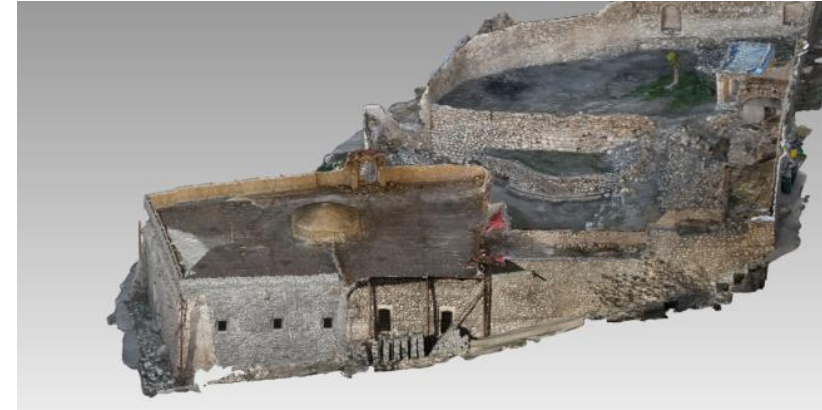

Figure 7. Example of the textured model created from the photogrammetric data set with missing parts supplementation, view from the East

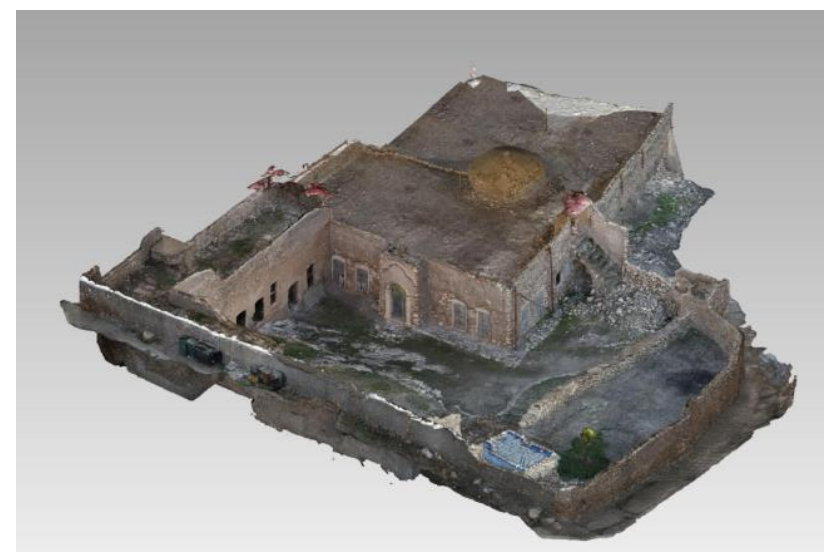

Figure 8. Sample of a textured model created from photogrammetric data set; view from the North

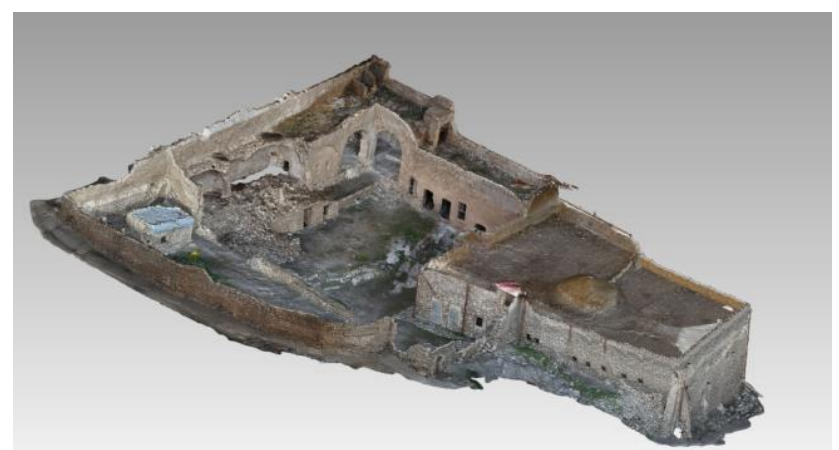

Figure 9. Example of the textured model created from photogrammetric data set with missing parts supplementation, view from the West

\section{RESULTS}

\subsection{Data processing}

Above all, two very detailed 3D models were created (fig.7-9). In terms of accuracy, it can be stated that the achieved accuracy is defined by the parameters of the Faro laser scanner. This means that the positioning accuracy of the object point on the short distance used (up to $10 \mathrm{~m}$ ) is around $2 \mathrm{~mm}$. Of course, accuracy depends also on the type of measured object; in this case, partially damaged building parts like pillars and vaults were measured, as were ruins and debris. All these features are parts of the whole 3D model. it can be said that from this point of view it is not important to define the millimetre accuracy and millimetre detail globally. In the shrine, 16 small reflecting targets were installed, originally intended for joining better scans. The distances between them (totally 12 distances between directly visible 
targets) were measured by the Leica Disto laser rangefinder. During data processing, all 98 measured point clouds were processed automatically using a correlation technique to one big point cloud. From statistics after automatic data joining it is defined that over 98 percent of the points have a positional error of up to $3 \mathrm{~mm}$, which is absolutely sufficient. No other method would give better results on a similar object. Finally, the measured values between the targets with the calculated values from the point cloud were compared. There is very important point on how it is possible to detect targets in a point cloud and how precise was the targeting with the Leica Disto distance meter. For laser scanning precision calculation, it is necessary to have a more accurate measurement at least for selected points. This is difficult to arrange in the field, especially when the laser scanner has a similar precision to short distances, such as a total station. From this reason, hand measured distances between targets were used for control only. Eight of the distance differences were up to $5 \mathrm{~mm}$, two up to $8 \mathrm{~mm}$ and one $1,2 \mathrm{~cm}$.

The first 3D model from the laser scanner (from phase one) was selected as reference model. All other (mainly photogrammetrical models) were transformed to this reference model.

\subsection{Photogrammetry}

Photogrammetrically created 3D models are more precise and have better texture, but they could be distorted due to poor geometric configuration (long and narrow models, big area models from many images, etc.). Our photogrammetrical models were created from thousands of photos taken from different places and directions, and the final model is robust. The final model scale was calculated from a reference laser scanned model. Two photogrammetrical models were created and used for the next analyses and works (due to better texture and details). At present, both 3D models (phase one and phase two) are finalized for object visualization and viewing in a virtual reality (VR) environment such as desired profiles. VR seems to be a very fruitful technology for visualization and analysis, mainly for the interior of buildings.

Orthophotos of all walls of the shrine were created, and then these were vectored into AutoCAD with the main purpose of a typical construction and static documentation as well as for the future reconstruction of the shrine. As a secondary result, 3D models of control pits were created and sent directly after photographing and data processing to static experts during phase one. After distant consultation with experts, other and deeper control pits and measurements were made. This is the advantage of displaying 3D models without having to visit a large number of on-site experts. Some GPR (ground penetrating radar) measurements were made, but the results were not surprising and not yet processed

\section{CONCLUSION}

Exact geodetic and geophysical documentation and survey of the Nahum's shrine on the basis of the available technical and material options were made. The total amount of both original and processed data is currently around 80GB. Part of the work was experiments with two types of data - photogrammetric terrestrial and aerial data and laser-scanned data. Based on the results of the project, it can be said that photogrammetric models are in this case superior to those of the laser scanner. Problems were occurred by shadows and poor lighting inside shrine. Some experiments were made by combining both data types using special software like Reality Capture, for example. Additional experiments were performed to transfer data to VR technology. In this case, it was not a fundamentally high accuracy, but especially the detail of the documentation became the basis for the reconstruction. Today's state is completely different, and so there is a unique VR technology that allows viewing a state that no longer exists. Outputs and results from measurements and experiments of this big and prestigious project deal with reconstruction and mainly for Prophet Nahum's shrine retrieval, the rare cultural monument for 3 religions.

\section{ACKNOWLEDGEMENTS}

This research was partially supported by a student's Internal grant of the Czech Technical University Nr. SGS19/048/OHK1/1T/11 and partially by a grant of the Czech Science Foundation Nr. 18-13296S. Many thanks to ARCH International and GemaArt group for support.

\section{REFERENCES}

Aslan, Z., 2016. Conservation of Cultural Heritage in the Arab Region. Sharjah: Centre for the Study of the Preservation and Restoration of Cultural Property. ISBN: 978-92-9077-243-9.

Barez, F. A., 2019. A Field Trip to Alqosh - ARCH International. [online] Available at: https://www.archinternational.org/2019/0 3/29/a-field-trip-to-alqosh/ [Accessed 15 Jul. 2019].

Barrile, V., Nunnari, A., Ponterio, R., 2016. Laser Scanner for the Architectural and Cultural Heritage and Applications for the Dissemination of the 3D Model. Procedia - Social and Behavioral Sciences, Vol. 223, pp.555-560.

https://doi.org/10.1016/j.sbspro.2016.05.342

Faltynova, M., Pavelka, K., Novy, P., Sedina, J., 2015. Complex Archaeological Prospection Using Combination of Nondestructive Techniques. ISPRS - International Archives of the Photogrammetry, Remote Sensing and Spatial Information Sciences, Vol. XL-5/W7, pp.141-146.

https://doi.org/10.5194/isprsarchives-XL-5-W7-141-2015

Falynova, M., Raeva, P., Poloprutsky, Z., Matouskova, E. and Housarova, E., 2016. Complex analysis and documentation of historical buildings using new geomatics methods. The Civil Engineering Journal, 2016-4(27). https://doi.org/10.14311/CEJ.2016.04.0027

Hassani, F., 2015. Documentation of cultural heritage techniques, potentials and constraints. 25th International CIPA Symposium 2015, Vol. XL-5/W7, pp.207-214.

https://doi.org/10.5194/isprsarchives-XL-5-W7-207-2015

Layard, A., H., 1853. Discoveries in the ruins of Nineveh and Babylon, Internet Archive. G. P. Putnam and Co. Retrieved 8 March 2018.

Matouskova, E., M. Hulkova, Sedina, J., 2016a. Historical Plasters Composition Detection Using Reflectance Spectroscopy. The Civil Engineering Journal, 2016-4(23). https://doi.org/10.14311/CEJ.2016.04.0023 
Matousková, E., Starkova, L., Pavelka, K., Novacek, K., Sedina, J., Faltynová, M., Housarová, E., 2016b. Using remotely sensed data for documentation of archaeological sites in northeaster Mesopotamia. ISPRS - International Archives of the Photogrammetry, Remote Sensing and Spatial Information Sciences, Vol. XLI-B5, pp.335-342.

https://doi.org/10.5194/isprsarchives-xli-b5-335-2016

Remondino, F., Barazzetti, L., Nex, F., Scaioni, M., Sarazzi, D., 2011. UAV photogrammetry for mapping and 3D modellingcurrent status and future perspectives. nt. Arch. Photogramm. Remote Sens. Spatial Inf. Sci., Vol. XXXVIII-1/C22, pp. 25-31. https://doi.org/10.5194/isprsarchives-XXXVIII-1-C22-25-2011

Sedina, J., Hulkova, M., Pavelka, K., Pavelka, jr, K., 2018a. RPAS for documentation of Nazca aqueducts. European Journal of Remote Sensing, Vol. 52(sup1), pp.174-181.

https://doi.org/10.1080/22797254.2018.1537684

Sedina, J., Pavelka, K., Reznicek, J., Matouskova, E. and Faltynova, M., 2015. Combining laser scanning and IBM technology in Cultural heritage. 15th International Multidisciplinary Scientific GeoConference SGEM 2015, Informatics, Geomatics and remote sensing. Vol. 1, pp. 61-68. https://doi.org/10.5593/SGEM2015/B21/S7.009

Sedina, J., Housarova, E., Raeva, P., 2017. Using of RPAS in precision agriculture. 17th International Multidisciplinary Scientific GeoConference SGEM 2017, Informatics, Geoinformatics and Remote Sensing. Vol. 17, pp. 331-338. https://doi.org/10.5593/sgem2017/23/S10.041

Sedina, J., Housarova, E., Raeva, P., 2018b. Using RPAS for the detection of archaeological objects using multispectral and thermal imaging. European Journal of Remote Sensing, Vol. 52(sup1), pp.182 -191.

https://doi.org/10.1080/22797254.2018.1562848 